\title{
Etude quantitative de quelques pigments de la Spiruline cultivée en Mauritanie en vue d'une valorisation nutritionnelle
}

\author{
Bocar Kalidou M'BAYE ${ }^{1 *}$, Baidy LÔ ${ }^{1}$ et Emmanuel BASSENE ${ }^{2}$ \\ ${ }^{1}$ Laboratoire de Chimie Alimentaire, Institut National de Recherches en Santé Publique de Nouakchott, \\ Mauritanie. BP : 695, Tel : 00222525.31 .75 \\ ${ }^{2}$ Laboratoires de Pharmacognosie et Botanique, Faculté de Médecine, de Pharmacie et d'Odonto-stomatologie \\ à l'Université Cheikh Anta Diop de Dakar, Sénégal. BP 5005, Tel : +221 $776438067 / 338245038$ \\ *Auteur correspondant, E-mail : bocar_kalidou@yahoo.fr
}

\section{RESUME}

La spiruline est une cyanobactérie comestible, extrêmement riche en protéine, en acides gras essentiels, en vitamines et en divers oligo-éléments. Elle est utilisée pour lutter contre la malnutrition infantile. Dans le but d'élucider les pigments constitutifs de la Spiruline cultivée en Mauritanie, des campagnes de prélèvements ont été effectuées. Cinquante un (51) échantillons de spiruline dont vingt huit (28) échantillons sous forme de spaghettis et Vingt trois (23) sous forme de poudre ont été prélevés d'Octobre à Décembre 2010. Les résultats de ces analyses ont montré que l'humidité qui caractérise la teneur en eau dans la spiruline varie de 5,1 à 9,6\%, la teneur en cendre varie de 7,1 à $10,2 \%$. La teneur en protéine est remarquablement élevée et varie de $51 \%$ à $87,5 \%$ par rapport au poids sec. La teneur en phycocyanines oscille entre $46 \%$ et $53 \%$. Les valeurs des caroténoïdes varient de $5,43 \mathrm{mg} / \mathrm{g}$ à $8,93 \mathrm{mg} / \mathrm{g}$. La spiruline peut être actuellement l'une des meilleures solutions pour la production simple d'un complément alimentaire de haute qualité.

(C) 2011 International Formulae Group. All rights reserved.

Mots clés : Spiruline, protéines, phycocyanines, caroténoïdes, Mauritanie.

\section{INTRODUCTION}

La spiruline par ses vertus nutritionnelles peut atténuer la malnutrition proteino-énergétique dans les pays en développement. La Spiruline est riche en protéines, en acide gras essentiels, en bétacarotène, en vitamine et en minéraux (Careri et al., 2001; Morist et al., 2001; Puyfoulhoux et al., 2001; Gomez et al., 2004). La spiruline nutritionnellement appréciable dont la teneur en protéine oscille entre $50 \%$ et $70 \%$ de son poids sec (Aviano et al., 2000; Falquet et Hurni, 2006). Cette teneur est fonction du moment de la récolte par rapport à la photopériodique, les valeurs les plus fortes étant obtenues au début de la période lumineuse (Sorto, 2003). La richesse de la Spiruline en protéique et en vitaminique a donné lieu à un essai de réhabilitation nutritionnelle à Dakar (Babadzhanov, 2004).

Dans la Spiruline le ß-carotène représente 40 à $80 \%$ des caroténoïdes (Costa 
et al., 2002). Selon Becker (1993), on trouve $13 \mathrm{mg} / \mathrm{kg}$ de tocophérol dans la spiruline sèche.

Le problème de la malnutrition protéino-énergétique continue à se poser avec acuité dans les pays en développement. Dans le but de déterminer les valeurs nutritionnelles de la Spiruline cultivée en Mauritanie nous allons élucider ses pigments constitutifs (phycocyanines, caroténoïdes, protéines).

\section{MATERIEL ET METHODES}

\section{Echantillonnage}

Le prélèvement des échantillons a été fait de manière aléatoire dans des boîtes stériles sur des lots de stockage. Au total cinquante un (51) échantillons ont été prélevés pour cette étude. Ces échantillons ont été analysés dans le Laboratoire de Chimie Alimentaire de l'Institut National de Recherches en Santé Publique (INRSP) de Nouakchott. Parmi ces échantillons, vingt huit (28) étaient sous forme de spaghettis et vingt trois (23) étaient sous forme de poudre, la période de prélèvement s'étendait d'Octobre à Décembre 2010. Ces échantillons avaient un goût normal, une couleur verte claire à l'exception de douze (12) échantillons qui avaient une couleur attirant le vert foncé.

\section{Matériel et Réactifs}

Les matériels utilisés sont: le Distillateur Kjeldahl de type UDK 140, une balance de précision de type PR 503 delta Range, un tube ou matras de minéralisation de $100 \mathrm{ml}$, un dispositif de chauffage, un dispositif d'absorption de vapeurs (trompe à vide), des billes de verre, un appareil de distillation, un mixeur ou mortier-pilon, une burette de $25 \mathrm{ml}$, un bécher de $250 \mathrm{ml}$, une pipette de $10 \mathrm{ml}$ avec un poire, un agitateur magnétique et un barreau aimanté. Les réactifs utilisés sont: l'acide sulfurique $95-96 \%$, l'acide sulfurique $0,1 \%$, la soude à $30 \%(300$ $\mathrm{g} /$ litre), l'acide borique $4 \%$, le catalyseur kjeldahl en pastilles, le rouge de méthyle $(0,1 / 100 \mathrm{ml})$.

\section{Méthodes d'analyse}

L'humidité a été déterminée par la méthode gravimétrique et le séchage a été effectué à l'aide d'une étuve de marque Italienne de type Titanox art A3-214-535 à $110{ }^{\circ} \mathrm{C}$ pendant 3 heures. Pour la détermination des protéines on utilise la méthode de kjeldahl en effectuant la minéralisation en présence de l'acide sulfurique $95-96 \%$, puis la distillation en présence de l'acide borique et de rouge de méthyle et enfin le titrage.

La méthode utilisée pour les phycocyanines est une décantation en présence de l'eau distillée autour de $4 \%$. Les teneurs des phycocyanines sont mesurées en faisant la différence des densités optiques à des longueurs d'onde $652 \mathrm{~nm}$ et $615 \mathrm{~nm}$ avec un Spectrophotomètre (cuve à trajet optique $11 \mathrm{~mm}) 722 \mathrm{~S}$ Beijing de marque chinoise. Pour la détermination des caroténoïdes on utilise une décantation en présence de l'alcool $90^{\circ}$ pendant $24 \mathrm{~h}$ dans un réfrigérateur puis on mesure la densité optique à $450 \mathrm{~nm}$ avec un Spectrophotomètre de $722 \mathrm{~S}$ Beijing marque chinoise.

\section{RESULTATS}

Le Tableau 1 donne les résultats détaillés (valeurs maximales, valeurs minimales, valeurs moyennes et écarts types) de tous les pigments constitutifs de la Spiruline étudiée. Les résultats de ces analyses ont montré que l'humidité varie de $5,1 \%$ à $9,6 \%$, la teneur en cendre varie de $7,1 \%$ à $10,2 \%$ (Tableau 1). La teneur en protéine varie de $51 \%$ à $87,5 \%$ (Tableau 1) par rapport au poids sec. La teneur en phycocyanines oscille entre $46 \%$ et $53 \%$ (Tableau 1). Les valeurs des caroténoïdes varient de $5,43 \mathrm{mg} / \mathrm{g}$ à $8,93 \mathrm{mg} / \mathrm{g}$ (Tableau 1$)$. 
Tableau 1 : Résultats des pigments constitutifs de la Spiruline étudiée.

\begin{tabular}{lccccc}
\hline Paramètres & Unités & Max. & Min. & Moy. & Ecart Types \\
\hline Humidité & $\mathbf{\%}$ & 10,20 & 5,10 & 7,08 & 0,96 \\
Cendres & $\mathbf{\%}$ & 10,20 & 7,11 & 8,33 & 0,98 \\
Protéines & $\mathbf{\%}$ & 87,50 & 51,62 & 59,99 & 5,5 \\
Caroténoïdes & $\mathbf{m g} / \mathbf{g}$ & 8,93 & 5,43 & 6,86 & 0,95 \\
Phycocyanine & $\mathbf{\%}$ & 53 & 43 & 48,97 & 1,6 \\
\hline
\end{tabular}

\section{DISCUSSION}

Des études ont montré un intérêt biologique relatif aux phycocyanines en raison de leur propriété antioxydant (Bhat et al., 2001). La teneur moyenne en phycocyanines trouvée au niveau de la Spiruline cultivée en

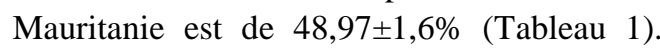
Cette teneur est dans la gamme des normes des critères édités par le Conseil Supérieur d'Hygiène Publique de France. Les caroténoïdes sont de puissants antioxydants capables de protéger nos cellules contre les attaques des radicaux libres et d'exercer ainsi une action préventive contre un certain nombre de maladies dégénératives. La valeur moyenne des caroténoïdes obtenue au niveau de la spiruline cultivée en Mauritanie est de $6,86 \pm 0,95 \mathrm{mg} / \mathrm{g}$ (Tableau 1).

Les teneurs en protéines trouvées par certains chercheurs oscillent entre $50 \%$ et $70 \%$. Ces résultats montrent que, du point de vu qualitatif, les protéines de la spiruline sont complètes car tous les acides aminés essentiels y figurent et représentent $47 \%$ du poids total des protéines (Loîc et al., 2008). La teneur moyenne en protéine obtenue au niveau de la Spiruline cultivée en Mauritanie est de $59,9 \pm 5,5 \%$. Toutes ces valeurs sont dans les normes des critères édités par le Conseil Supérieur d'Hygiène Publique de France pour les algues alimentaires.

\section{Conclusion}

Les résultats trouvés dans cette étude nous montrent que la Spiruline cultivée en Mauritanie regorge en abondance de phycocyanines $(48,97 \pm 1,6 \%)$, de caroténoïdes $(6,86 \pm 0,95 \mathrm{mg} / \mathrm{g})$ et de protéines
$(59,9 \pm 5,5 \%) . \quad \mathrm{Au} \quad \mathrm{vu}$ des propriétés nutritionnelles sans égales de la spiruline, il apparaît clairement que sa culture dans les pays frappés par la malnutrition devient indispensable. La spiruline peut être un outil potentiel dans les programmes de lutte contre la malnutrition infantile en Mauritanie.

En Mauritanie, la spiruline est cultivée à petite échelle. Sa production à grande échelle est intéressante et peut s'effectuer dans les régions de l'intérieur qui sont très favorables à la culture de spiruline puisque réunissant toutes les conditions. La spiruline n'est pas connue en Mauritanie, ce qui fait défaut à la promotion et à la sensibilisation.

\section{REFERENCES}

Avino P, Carconi PL, Lepore L, Moauro. 2000. Nutritionnelle et les propriétés écologiques des produits d'algues utilisés pour une alimentation saine. INAA et ICP-AES., 244(1): 247-252.

Babadzhanov AS. 2004. Composition chimique des Spirulina platensis cultivés en Ouzbékistan. Chimie Naturelle des Composés, 3: 40.

Becker EW. 1993."Development of spirulina Research in a Developing CountryIndia". Bull. Inst. Océano Monaco, 12: 49-57.

Bhat, Vadiraja B, Madyastha KM. 2001. Scavenging of peroxynitrite by phycocyanin and Phycocyanobilin from spirulina platensis: protection against oxidative damage to DNA. Chemical Biology Unit, Jawaharlal Nehru Centre for Advanced Scientific Research 
Bangalore, India, p. 286, 1, 228.

Careri M, Furlattini L, Mangia A, Musci M, Anklam E, Theobald A, Von Holst C. 2001. Supercritical fluid extraction for liquid chromatographic determination of carotenoids in Spirulina Pacifica algae: a chemometric approach. $J$. Chromatography A, 912: 61-71.

Costa JAV, Colla LM, Duarte P, Kabke K, Weber A. 2002. Modelling of Spirulina platensis growth in fresh water using response surface methodology. World Journal of Microbiology and Biotechnology, 18: 603-607.

Falquet J, Hurni JP. 2006. Spiruline, Aspects Nutritionnels. Antenna Technologies; 41.

Gomez Coronado DJ, Ibanez E, Ruperez FJ, Barbas C. 2004. Tocopherol measurement in edible products of vegetable origin. $J$. Chromatography. A, 1054(1-2): 227-33.

Loîc C, Marie JL, Romain A. 2008. La spiruline peut elle être un atout pour la Santé et le développement en Afrique. IRD: Marseille ; 49 p.

Morist A, Montesinos JL, Cusido JA, Goclia F. 2001. Recovery and treatment of Spirulina platensis cel1s cultured in acontinuous photobioreactor to be used as food. Process Biochemistry, 37: 535-547.

Puyfoulhoux G, Rouanet JM, Besançon P, Baroux B, Baccou JC, Caporiccio B. 2001. Iron Availability from iron-fortified spirulina by an in vitro digestion/Caco-2 cell culture model. J. Agric. Food Chem., 49: 1625-1629.

Sorto M. 2003. Utilisation et consommation de la Spiruline au Tchad. (2ème Atelier international). Voies alimentaires d'amélioration des situations nutritionnelles. Food-based approaches for a healthy nutrition, Ouagadougou, 23$28 / 11 / 2003$. 